\title{
VIRTUALIZAÇÃO DO INQUÉRITO POLICIAL E EFICIÊNCIA: TÍPICO REFLEXO DA ERA INFORMACIONAL
}

\author{
Marcelo Guerra Martins* \\ Eduardo Sorrentino de Alcântara** \\ Fábio Gallinaro***
}

SUMÁRIO: Introdução; 2 Instrumentos preliminares da investigação criminal no contexto da sociedade da informação; 3 Natureza jurídica do inquérito policial e a questão do sigilo; 4 Crise do inquérito policial: Morosidade, insipiência e desvio de função; 5 Experiências em andamento; 6 Conclusões; Referências.

RESUMO: O presente trabalho analisa aspectos jurídicos e sociais dos instrumentos preliminares de investigação criminal no Brasil, com destaque para o inquérito policial, diante do avanço tecnológico das últimas décadas, o que vem, aos poucos, promovendo a transição da tradicional forma escrita (no papel), para a eletrônica. Dentre as questões analisadas, destacam-se os instrumentos preliminares da investigação no contexto da sociedade da informação; a natureza jurídica do inquérito policial; o tratamento sigiloso com objetivo de não prejudicar o sucesso das investigações e de preservar a dignidade dos investigados e das vítimas; a crise que atinge a sistemática do inquérito policial e as experiências já realizadas na adoção do inquérito na forma eletrônica. O método utilizado é o qualitativo com resultados obtidos por indução.

PALAVRAS-CHAVE: Sociedade da informação; Inquérito policial eletrônico; Sigilo das investigações; Eficiência.

\section{VIRTUAL POLICE INQUIRIES AND EFFICIENCY: A T YPICAL CONSEQUENCE OF THE INFORMATION ERA}

\begin{abstract}
Juridical and social aspects in preliminary instruments of criminal investigation in Brazil, with special reference to police inquiry, are analyzed. Recent technological advances have triggered the transition from the written traditional form (on paper) to the electronic mode. Issues include preliminary investigation tools within the context of information society, the juridical nature of police enquiries,

\footnotetext{
"Doutor em Direito do Estado pela Universidade de São Paulo (USP). Docente do Mestrado em Direito no Centro Universitário das Faculdades Metropolitanas Unidas. Brasil.

${ }^{*}$ Mestrando no Programa de Mestrado em Direito da Sociedade da Informação na FMU. Docente da graduação em Direito no Centro Universitário das Faculdades Metropolitanas Unidas (FMU), Brasil.

**** Mestrando no Programa de Mestrado em Direito da Sociedade da Informação na FMU. Docente da graduação em Direito no Centro Universitário das Faculdades Metropolitanas Unidas (FMU), Brasil
} 
the secrecy involved to not impair investigations and preserve the dignity of people investigated and of victims, the crisis affecting police enquiries and experiences in the adoption of electronic forms. The qualitative method has been used, with induction-obtained results.

KEY WORDS: Society of information; Electronic police inquiry; Secrecy of investigations; Efficiency.

\section{VIRTUALIZACIÓN DEL INVESTIGACIÓN POLICIAL Y EFICIENCIA: TÍPICO REFLEJO DE LA ERA INFORMACIONAL}

RESUMEN: En el presente estudio se analiza aspectos jurídicos y sociales de los instrumentos preliminares de investigación criminal en Brasil, con hincapié a la investigación policial, delante del avance tecnológico de las últimas décadas, lo que viene, poco a poco, promoviendo la transición de la tradicional forma escrita (en papel), a la electrónica. Entre las cuestiones analizadas, se destacan los instrumentos preliminares de la investigación en el contexto de la sociedad de la información; la naturaleza jurídica de la investigación policial; el tratamiento confidencial con objetivo de no perjudicar el éxito de las investigaciones y de preservar la dignidad de los investigados y de las víctimas; la crisis que logran la sistemática de la investigación policial y las experiencias ya realizadas en la adopción de la investigación en la forma electrónica. El método utilizado es el cualitativo con resultados obtenidos por inducción.

PALABRAS CLAVE: Sociedad de la información; Investigación policial electrónico; Secreto de las investigaciones; Eficiencia.

\section{INTRODUÇÃO}

O presente artigo, fruto de pesquisa desenvolvida no mestrado em Direito pelo Centro Universitário das Faculdades Metropolitanas Unidas, São Paulo, Brasil, dentro da linha de pesquisa Decisão Jurídica e Monopólio do Estado, aborda tópicos referentes aos impactos dos avanços tecnológicos nos trabalhos policiais de persecução penal, notadamente a primeira fase, conhecida como investigatória ou de inquérito policial. 
A relevância do tema se justifica em face de sua ligação com a denominada sociedade da informaçã $0^{04}$, período histórico vivido pela humanidade em que dados, informações e conhecimento circulam globalmente a grandes velocidades, o que, evidentemente, gera reflexos em todas as searas da vida em sociedade, sendo o direito apenas uma delas. Justamente por isso, o tema escolhido também se entrelaça com Direitos da Personalidade dos investigados e vítimas de crimes, notadamente a privacidade e a intimidade que devem, efetivamente, ser protegidos pelas autoridades policiais contra "vazamentos" que possam comprometer a reputação de alguém antes mesmo da denúncia que inclusive pode chegar a não ser ofertada.

A adoção do inquérito policial eletrônico também se liga a uma questão de interesse público, ou seja, a celeridade e a eficiência da persecução penal pelo Estado, de modo a não apenas punir os infratores, mas, sobretudo, servir de elemento dissuasório do cometimento de novos delitos. De acordo com dados do Conselho Nacional do Ministério Público, até abril de 2012, do total de 136,8 mil inquéritos abertos até dezembro de 2007 para investigar homicídios, somente 10.168 se converteram em denúncias (menos de 10\%) e 39.794 foram arquivados. Os demais 85 mil inquéritos ainda se encontram sem solução, "em aberto" 05 , o que, em termos de constatação de materialidade e autoria, coloca numa espécie de limbo de indefinição mais da metade dos procedimentos, mesmo após vários anos.

Esses números indicam que muito provavelmente existam sérias deficiências quanto à capacidade do atual sistema de investigação policial produzir resultados específicos (identificação de materialidade e autoria) de forma célere, sendo certo que o passar do tempo é aliado da prescrição penal. Nessa linha, quais ferramentas permitiriam melhorar o sistema, mas preservando os direitos da personalidade dos investigados e vítimas? Obviamente, as respostas, além de complexas, não são únicas, não sendo possível tentar persegui-las todas nas breves linhas que se seguirão.

Porém, acreditamos que, dentre essas ferramentas possíveis (não a única, obviamente), a virtualização plena do inquérito policial é uma das mais relevantes, notadamente porque com o abandono do papel haverá a extinção de tarefas mera-

\footnotetext{
${ }^{04}$ Conforme Alain Herscovici, "esta transformação modifica todos os processos sociais, dos processos produtivos até as modalidades de funcionamento das instituições e de consumo dos bens culturais" (HERSCOVICI, Alain. A sociedade em rede e a universalização do mercado: elementos de análise. Revista Electrónica Internacional de Economía de las Tecnologías de la Información y de la Comunicación, n. 2, jul./ago. 2000. p. 28). Disponível em: < https://seer.ufs.br/index.php/eptic/article/view/320/295> . Acesso em: 23 fev. 2018.

${ }^{05}$ BRASIL. Estratégia Nacional de Justiça e Segurança Pública. Meta 2 - a impunidade como alvo - diagnóstico da investigação de homicídios no Brasil. Brasília, 2012. Disponível em: < http://www.cnmp.mp.br/portal/images/ stories/Enasp/relatorio_enasp_FINAL.pdf > . Acesso em: 03 abr. 2018.
} 
mente burocráticas ( $v$.g. confecções de certidões, juntada física de documentos, extração de fotocópias, expedição de ofícios e intimações, remessa dos autos ao Fórum ou ao Ministério Público etc.), com potencial benefício em termos de celeridade.

É certo que a virtualização do inquérito policial também representará economia de recursos aos cofres públicos. Segundo dados do Setor de Tecnologia da Informação da Polícia Civil de São Paulo, em 2017, foram instaurados quase 400.000 inquéritos, sendo que um único Auto de Prisão em Flagrante pode requerer a utilização de dezenas de folhas de papel ${ }^{06}$.

Há também o fato de os processos judiciais estarem adotando a forma eletrônica, o que, aliás, já foi implantado no Poder Judiciário Paulista, sendo certo que, desde 30 de novembro de 2016, ${ }^{07}$ não há mais o recebimento de qualquer demanda nova em meio físico, devendo os processos antigos ser submetidos à digitalização. Nesse contexto, a manutenção dos inquéritos policiais em papel representa um conflito entre paradigmas e concepções acerca da operacionalização de procedimentos, dificultando inclusive o normal andamento dos inquéritos quando remetidos ao Poder Judiciário para as mais diversas providências.

Em termos de metodologia, o presente texto se apresenta como um estudo teórico (revisão bibliográfica e de legislação), com abordagem de índole qualitativa com resultados obtidos por induçã $0^{08}$, ficando advertido não ser intenção dos autores firmarem verdades absolutas ou palavras finais sobre o tema. Ao contrário, críticas e sugestões são esperadas e bem-vindas.

\section{INSTRUMENTOS PRELIMINARES DA INVESTIGAÇÃO CRIMINAL NO CONTEXTO DA SOCIEDADE DA INFORMAÇÃO}

A humanidade passa por um ciclo de em que a criação, o processamento, o armazenamento e a difusão de ideias, informações e de conhecimento passam, cada

${ }^{06}$ SÃO PAULO (Estado). Secretaria de Segurança Pública. Dados estatísticos do Estado de São Paulo. Disponível em: < http://www.ssp.sp.gov.br/Estatistica/Pesquisa.aspx> $>$. Acesso em: 25 mar. 2018.

${ }^{07}$ SÃO PAULO (Estado). Tribunal de Justiça. 100\% digital. Disponível em: < http://www.tjsp.jus.br/CemPor CentoDigital>. Acesso em: 22 mar. 2018.

${ }^{08}$ Especificando, há a apresentação da descrição e análise dos dados numa síntese narrativa, mediante busca de significados num contexto jurídico-social específico (fases preliminares da persecução penal), sendo os autores os instrumentos principais da construção da pesquisa. Por fim, utiliza-se o enfoque indutivo para as conclusões, ou seja, mediante a realização de generalizações das observações limitadas e especificadas pelos pesquisadores. 
vez mais, a ter o papel de protagonista nos arranjos socioeconômicos das diversas sociedades. Vive-se atualmente na denominada sociedade da informação. Segundo aduz Paulo Siqueira Júnior ${ }^{09}$ "Na era agrícola, a terra se configurava como o fator primordial da geração de riquezas. Na era industrial a riqueza surge da máquina a vapor e da eletricidade. Na era do conhecimento, a informação e o conhecimento são os atores centrais da produção econômica”.

$\mathrm{O}$ desenvolvimento de computadores e tecnologias ligadas à informática $\mathrm{e}$ transmissão de dados foi crucial à fixação dessa nova conjuntura social, cujo grande impulso se deu a partir do surgimento da versão comercial da internet que, na visão de Manuel Castells, se mostra como "um meio de comunicação que permite, pela primeira vez, a comunicação de muitos com muitos, num momento escolhido, em escala global". Aliás, não é exagero afirmar que "The global age is not abead of us; we are already in it" 10 .

Essa revolução digital, conforme Irineu Francisco Barreto Júnior ${ }^{11}$, faz com que sejam dissolvidas "as fronteiras entre telecomunicações, meios de comunicação de massa e informática". De fato, de poucas décadas para cá, modificaram-se profundamente tanto a forma quanto a velocidade da aquisição e transmissão de conhecimento. Tanto isso é verdade que, segundo Pierre Lévy, "a extensão do ciberespaço acompanha e acelera uma virtualização geral da economia e da sociedade"12.

Em suma, salvo raríssimas exceções, é possível afirmar que todas as ações e interações humanas encontram-se, de alguma maneira, ligadas ao mundo virtual, seja em termos de produção ou aquisição de informações e conhecimento, seja no que tange à propagação de ideias e, sobretudo, no engendramento das mais diversas formas de comunicação.

É dentro desse contexto de alta tecnologia cibernética e comunicacional que vigoram os preceitos do Código de Processo Penal - CPP, decreto-lei n ${ }^{\circ} 3.689$, de 03 de outubro de 1941, época em que a ora vetusta datilografia era considerada um grande avanço. Pois bem, nos termos do art. $5^{\circ}$ do CPP, o inquérito policial poderá ser instaurado de ofício ou mediante requisição da autoridade judiciária ou do Ministério Público, ou a requerimento do ofendido ou de quem tiver qualidade para representá-lo.

\footnotetext{
${ }^{09}$ SIQUEIRA JÚNIOR, Paulo Hamilton. Habeas data: remédio jurídico da sociedade da informação. In: PAESANI, Liliana Minardi (Coord.). O direito na sociedade da informação. São Paulo: Atlas, 2007, p. 255.

${ }^{10}$ MATTELART, Armand. The information society. Trad. p/ ingles Susan G Taponier e James A. Cohen. London: SAGE Publications, 2003, p. 91. Em tradução livre: "A era global não está à frente, já estamos nela".

${ }^{11}$ BARRETO JR, Irineu Francisco. Atualidade do conceito de sociedade da informação para a pesquisa jurídica. In: PAESANI, Liliana Minardi (Coord.). O direito na sociedade da informação. São Paulo: Atlas, 2007, p. 62.

12 LÉVY, Pierre. Cibercultura. São Paulo: Editora 34, 2. ed., 6. reimp., 2007, p. 49.
} 
Consoante estabelece o art. 40 do CPP, quando, em autos ou papéis de que conhecerem, os juízes ou tribunais verificarem a existência de crime de ação pública, remeterão ao Ministério Público as cópias e os documentos necessários ao oferecimento da denúncia. Não havendo, contudo, os elementos indispensáveis ao oferecimento da exordial acusatória, a autoridade judiciária ou o Ministério Público terão a faculdade de requisitar a instauração de inquérito policial.

$\mathrm{O}$ ofendido ou seu representante legal também poderão requerer a instauração de inquérito, mediante petição endereçada à autoridade policial, contendo a narração do fato, com todas as circunstâncias, a individualização do suspeito ou, ao menos, seus sinais característicos e as razões de convicção ou de presunção de ser ele o autor da infração, bem como a nomeação das testemunhas, entre outros meios de prova. A prisão em flagrante, por outro lado, também é uma das maneiras de instauração do inquérito policial, admitida a sua consecução sem mandado judicial pela própria Constituição Federal (art. $\left.5^{\circ}, \mathrm{LXI}\right)$, porquanto manifesta a evidência probatória quanto ao fato e sua autoria.

Seja qual for a maneira de instauração do inquérito policial, afigura-se bastante factível que sua instrumentalização ocorra por intermédio dos recursos tecnológicos hoje existentes, de modo a facilitar o trabalho encetado nas Delegacias de Polícia, visando à elucidação dos crimes e o descobrimento da respectiva autoria com mais celeridade e precisão.

Nesse diapasão, por exemplo, nada impede a lavratura do auto de prisão em flagrante, com a respetiva colheita das declarações, depoimentos e interrogatório, mediante gravação magnética ou eletrônica, como já ocorre com o processo judicial criminal $^{13}$, desde sem que não haja qualquer desrespeito aos direitos e garantias fundamentais do detido. Nesse ponto, segundo explana Augusto Rossini ${ }^{14}$ :

A correta obtenção da prova digital é dos temas mais complexos, especialmente em razão do célere avanço tecnológico que altera rápida e sensivelmente o modo de atuar quando a autoridade policial, o membro do Ministério Público ou qualquer outra autoridade responsável pela investigação (tanto criminal quando em sede de

\footnotetext{
${ }^{13}$ Art. 405 do CPP: Do ocorrido em audiência será lavrado termo em livro próprio, assinado pelo juiz e pelas partes, contendo breve resumo dos fatos relevantes nela ocorridos. $\$ 1^{\circ}$. Sempre que possível, o registro dos depoimentos do investigado, indiciado, ofendido e testemunhas será feito pelos meios ou recursos de gravação magnética, estenotipia, digital ou técnica similar, inclusive audiovisual, destinada a obter maior fidelidade das informações.

${ }^{14}$ ROSSINI, Augusto Eduardo de Souza. Breve ensaio sobre a tutela punitiva na sociedade da informação, suas esferas de proteção e recentes conquistas. In: PAESANI, Liliana Minardi (Coord.). O Direito na Sociedade da Informação II. São Paulo: Atlas, 2008, p. 140.
} 
inquérito civil) estiver diante de um procedimento apuratório de práticas de infrações da espécie tratada. Contudo, a despeito disso, os princípios constitucionais devem sempre ser aplicados, porquanto paradigmas para o devido processo legal.

De outra parte, além do inquérito policial, é oportuno mencionar outro instrumento preliminar de investigação. Trata-se do termo circunstanciado, utilizado para as infrações penais de menor potencial ofensivo e previsto no art. 69, caput, da lei $\mathrm{n}^{0}$ 9.099/95. Revela-se um procedimento simplificado, em harmonia com os princípios da simplicidade, informalidade, economia processual e celeridade que regem os Juizados Especiais. Todavia, no presente texto, a atenção está precipuamente voltada ao inquérito policial.

Portanto, inquérito policial e termo circunstanciado são instrumentos que se diferenciam notadamente em relação aos custos de elaboração, o que indiscutivelmente também se aplica ao formato digital dos instrumentos preliminares de investigação. Nesse tópico, Gustavo Junqueira e Paulo Henrique Fuller ${ }^{15}$ aludem que

O inquérito policial, peça informativa de cunho administrativo, dirigida ao acusador para fornecer elementos que deem justa causa à denúncia/queixa, resulta em gasto de tempo e recursos por parte do Estado. Em causas de menor potencial ofensivo, tal esforço parecia desproporcional, pelo que o procedimento foi transformado em simples e direto relato de diligências, como a oitiva dos envolvidos, restringindo-se na maioria das vezes a dados disponíveis na repartição policial. A redução de tais elementos na forma escrita dá conteúdo ao termo circunstanciado. Há que se lembrar, ainda, em prol da simplicidade, que o objetivo é sempre a solução consensual, e não o início do processo.

Em suma, o termo circunstanciado traz em seu bojo a notícia do crime, diligências imprescindíveis e, caso seja necessário, as requisições de eventuais perícias cabíveis no caso concreto. Sendo assim, com o advento da lei $\mathrm{n}^{\circ}$ 9.099/95, o instrumento em testilha passou a ser lavrado com bastante simplicidade, não se devendo perder, contudo, os informes suficientes a nortear o acusador para o oferecimento da denúncia ou da queixa-crime.

Tratando-se o inquérito policial de um instrumento de maior complexidade e sendo tecnologicamente possível a sua instauração no formato digital, com mui-

\footnotetext{
15 JUNQUEIRA, Gustavo Octaviano Diniz; FULLER, Paulo Henrique Aranda. Legislação penal especial. 6. ed. São
} Paulo: Saraiva, 2010, p. 479. vol. 1. 
to mais razão e conveniência é de se admitir a lavratura do termo circunstanciado em modo virtual, dado que nesse procedimento simplificado se exige uma resposta mais rápida por parte do Estado, não só em obediência ao princípio da celeridade, mas também para se evitar possível prescrição da pretensão punitiva em virtude das diminutas penas cominadas para as infrações penais de menor potencial ofensivo.

\section{NATUREZA JURÍDICA DO INQUÉRITO POLICIAL E A QUESTÃO DO SIGILO}

Os procedimentos preliminares de investigação criminal (inquérito e termo circunstanciado) são considerados inquisitórios, eis que suas atividades se concentrarem em uma única autoridade, sendo prescindível, para a sua atuação, a provocação de qualquer das partes. Em outras palavras, a autoridade age de ofício e de maneira discricionária (não arbitrária), sempre visando elucidar o delito e identificar a respectiva autoria. Desse modo, não se aplicam os princípios constitucionais do contraditório e da ampla defesa na fase investigativa, uma vez que não há uma acusação formal em desfavor daquele que se encontra sob investigação.

Entrementes, a lei $\mathrm{n}^{\mathrm{o}}$ 13.245, de 12 de janeiro de 2016, alterou o Estatuto da Advocacia e estabeleceu, em seu art. $7^{\circ}$, inciso XXI, alínea $a$, que constitui direito do advogado assistir a seus clientes investigados durante a apuração de infrações, sob pena de nulidade absoluta do respectivo interrogatório ou depoimento e, subsequentemente, de todos os elementos investigatórios e probatórios dele decorrentes ou derivados, direta ou indiretamente, podendo, inclusive, no curso da respectiva apuração apresentar razões e quesitos.

Nesse contexto, ainda que considerados os termos da referida legislação, não há falar em perda da característica inquisitiva do procedimento investigatório policial, tendo em vista que a novatio legis citada estabelece, tão somente, a possibilidade de o advogado assistir seus clientes, no sentido de orientá-los, por exemplo, no momento do interrogatório, instruindo-os acerca de quais perguntas deve responder ou não ${ }^{16}$.

De outra parte, o art. $9^{\circ}$ do CPP estabelece que todas as peças do inquérito policial serão, num só processado, reduzidas a escrito ou datilografadas e, neste

\footnotetext{
${ }^{16}$ É bem verdade que, com a edição da nova lei, foi expressamente conferida a possibilidade de apresentação de razões e quesitos. No entanto, tal procedimento já vinha sendo utilizado por advogados que acompanhavam seus clientes durante a tramitação do inquérito.
} 
caso, rubricadas pela autoridade. O dispositivo supramencionado se coaduna com a finalidade do inquérito policial que tem por objetivo a apuração de um fato que configure infração penal e a sua autoria, visando servir de base para a ação penal. Seria inimaginável, por conseguinte, a existência de uma investigação verbal. Todavia, as expressões "escrito ou datilografadas" podem dar a entender que o inquérito não comportaria a forma eletrônica, ou seja, deveria ser sempre formalizado em papel.

É incontroverso que os elementos formadores dos autos do inquérito policial devem ser reduzidos a termo e, nesse passo, o meio previsto no art. $9^{\circ}$, do CPP para a sua materialização, qual seja, datilografado, deve ser considerado diante do disposto da lei no $11.900 / 09$, por meio de uma interpretação analógica. Daí resulta considerar possível que, ao invés de datilografado, adote o inquérito o formato eletrônico, o mesmo valendo para o termo circunstanciado.

Nesse caminho de evolução, o próprio CPP dispõe no $\S 1^{\circ}$ do art. 405, que, sempre que possível, o registro do investigado, indiciado, ofendido e testemunhas será feito pelos meios ou recursos de gravação magnética, estenotipia, digital ou técnica similar, inclusive audiovisual, destinada a obter maior fidelidade das informações.

De outra parte, a lei $n^{0}$ 11.419/2006 (Lei do Processo Eletrônico), impôs a necessidade de adaptação do Judiciário "do papel" e "da máquina de escrever" à era digital, o que trouxe, também, a necessidade de a Polícia Judiciária, responsável pela condução dos inquéritos policiais, de se adaptar e acompanhar tais transformações tecnológicas estabelecidas pela sociedade da informação. Portanto, juridicamente falando, nada impede que os instrumentos preliminares de investigação criminal adotem a forma virtual.

Noutro giro, o disposto no art. 20 do CPP prevê que a autoridade assegurará no inquérito o sigilo necessário à elucidação do fato ou exigido pelo interesse da sociedade. O mencionado dispositivo tem por escopo evitar que a publicidade das provas colhidas e aquelas que a autoridade porventura pretenda produzir não prejudique a investigação, sendo certo que, mesmo diante da virtualização do inquérito policial, não ficará abalado o direito previsto no art. $7^{\circ}$, inciso XIV, da lei no 8.906/94 (Estatuto da $\mathrm{OAB}$ ), sendo no mesmo sentido a Súmula Vinculante $\mathrm{n}^{\mathrm{O}} 14$, do Supremo Tribunal Federal. ${ }^{17}$

\footnotetext{
${ }^{17}$ Súmula Vinculante ${ }^{\circ}$ 14: É direito do defensor, no interesse do representado, ter acesso amplo aos elementos de prova que, já documentados em procedimento investigatório realizado por órgão com competência de polícia judiciária, digam respeito ao exercício do direito de defesa.
} 
É óbvio que algumas diligências encetadas pela autoridade exigem sigilo absoluto, sob pena de serem frustrados os objetivos da investigação ou, até mesmo, de colocar em risco a segurança dos policiais nela envolvidos. Nesse diapasão, o próprio Estatuto da $\mathrm{OAB}$, em seu art. $7^{\circ}, \S 11$, inserido pela lei $\mathrm{n}^{0} 13.245$, de $12 \mathrm{de}$ janeiro de 2016, assegura que a autoridade competente poderá delimitar o acesso de advogados aos elementos de prova relacionados a diligências em andamento e ainda não documentadas nos autos, quando houver risco de comprometimento da eficiência, da eficácia ou da finalidade das diligências.

Logo, por exemplo, durante eventual infiltração de agentes policiais para desmantelamento de uma organização criminosa (lei $n^{0} 12.850 / 13$ ) ou no curso da interceptação telefônica judicialmente autorizada (lei $n^{0}$ 9.296/96), o acesso de advogados a tais diligências poderá (quiçá deverá) ser restringido.

É certo que ao cabo da infiltração ou mesmo da gravação telefônica, uma vez que as diligências se encontrem devidamente formalizadas (ou virtualizadas) no bojo do respectivo inquérito policial, todo material investigativo ficará disponível ao advogado autorizado a acessar o seu conteúdo, independentemente de o inquérito ostentar a forma material (papel) ou eletrônica.

Todavia, o sigilo no inquérito deve ser guardado não somente por uma questão de interesse público, no sentido de proteger o correto deslinde das investigações, mas, sobretudo, com vistas a resguardar as esferas privadas dos investigados e das vítimas da curiosidade alheia, tão ávida e presente em nossos dias. Com efeito, tratando-se de mera investigação, enquanto não houver a oferta da competente denúncia por parte do Ministério Público (ou do legitimado a tanto nas ações penais privadas), é de se supor ainda existirem elementos suficientes a demonstrar a materialidade e indícios de autoria.

Após a denúncia, pressupondo-se, então, que as investigações resultaram demonstrar prova da materialidade e, ao menos, indícios de autoria, a situação se transmuda e o que antes era sigiloso dá lugar à publicidade, cuja previsão é de índole constitucional (art. $\left.5^{\circ}, \mathrm{LX}\right)$. A regra é que exista ampla publicidade do processo penal, podendo haver limitações quando o interesse social ou a intimidade ${ }^{18}$ assim

\footnotetext{
${ }^{18}$ Igualmente o sigilo preserva direitos da personalidade da vítima, notadamente em crimes sexuais. Aliás, em relação ao ofendido, o sigilo pode se estender durante o trâmite processual, nos termos do $\S 6^{\circ}$ do art. 201 do $\mathrm{CPP}$, cuja redação prevê: "O juiz tomará as providências necessárias à preservação da intimidade, vida privada, honra e imagem do ofendido, podendo, inclusive, determinar o segredo de justiça em relação aos dados, depoimentos e outras informações constantes dos autos a seu respeito para evitar sua exposição aos meios de comunicação".
} 
exigirem (arts. $5^{\circ}, \mathrm{LX} \mathrm{c/c}$ art. 93, IX, da CF/88; arts. 20; 483 e 792, §2 ${ }^{\circ}$ todos do CPP). Considerando a possibilidade de, ao final das investigações, não terem sido apurados indícios razoáveis de autoria, eventuais "vazamentos" acerca do conteúdo do inquérito policial provavelmente causaria danos à privacidade, intimidade e honra de pessoas que, não obstante num primeiro momento terem sido consideradas potenciais autores do delito investigado, não sejam formalmente indiciadas pela autoridade policial ao final do procedimento.

É bem sabido que o fato de alguém se encontrar sob investigação policial quase sempre resulta numa pecha negativa sobre o indivíduo, dado a quase que inexorável perda de respeitabilidade social. Não raramente a pessoa investigada passa a ser alvo de fofocas dos vizinhos, maledicências, "olhares tortos" etc. O que não dizer, então, se o conteúdo das investigações chegar ao conhecimento público? Nesse ponto, os direitos da personalidade acima aludidos podem ser atingidos de maneira irreversível, ainda mais se ocorrer propagação por meio da mídia (escrita ou falada) ou da própria internet.

Um dos mais notórios casos de condução desastrada de um inquérito policial ocorreu em 1994, na cidade de São Paulo e ficou conhecido como "o caso da Escola de Base". Os então donos do estabelecimento foram acusados por duas mães de alunos da prática de pedofilia. Ocorre que, na ocasião, "o delegado responsável pelo caso havia afirmado a jornalistas, antes da conclusão das investigações, que era grande a possibilidade de a história ser verdadeira"19. O estrago não poderia ter sido pior: a autoridade não apenas deixou de cuidar para que as investigações se completassem sob o indispensável sigilo, mas divulgou detalhes e sua opinião perante a mídia nacional. Entretanto,

[...] com o andamento das investigações, todos os envolvidos foram inocentados. Nenhuma prova de que teriam cometido os abusos foi encontrada e o processo foi arquivado. Era tarde demais. As vidas dessas seis pessoas já estavam completamente destruídas, em grande parte por causa das notícias veiculadas pela mídia.

Se eventos como esse puderam ocorrer num inquérito policial tradicional (em papel), na hipótese de o procedimento adotar a forma eletrônica é preciso que o cuidado com a segurança dos respectivos sistemas de informática seja redobrado,

\footnotetext{
${ }^{19}$ PAIERO, Denise. Escola base: um caso que não pode ser esquecido. Portal Mackenzie, 13/04/2017. Disponível em: $\quad<$ http://portal.mackenzie.br/fakenews/noticias/arquivo/artigo/escola-base-um-caso-que-nao-pode-ser-esquecido/> . Acesso em: 02 abr. 2018.
} 
na medida em que, sabidamente, o ambiente virtual facilitaria a propagação e a replicação em massa do conteúdo das investigações, causando danos muito mais expressivos. Portanto, além da conduta adequada a ser adotada por autoridades, investigados e advogados, os sistemas devem promover proteção suficiente contra interceptação dos dados eletrônicos armazenados e em trânsito.

Pensamos que esse tipo de preocupação merece atenção, não sendo raras notícias de invasões ilícitas de sistemas (sites ou portais) de instituições públicas, Tribunais e da própria Polícia, com vazamento de informações sensíveis. Nesse sentido, por exemplo, recentemente, a "página da Secretaria de Segurança Pública do Maranhão (SSP/MA) foi atacada por hackers na noite desse domingo (12). A invasão foi assumida pelo hacker "ProtoWave", que durante uma hora aproximadamente praticou o crime cibernético"20.

\section{CRISE DOS INSTRUMENTOS PRELIMINARES DE INVESTIGAÇÃO: MOROSIDADE, INSIPIÊNCIA E DESVIO DE FUNÇÃO}

Como já demonstrado, os instrumentos preliminares de investigação possuem a precípua finalidade de reunir subsídios para a eventual propositura da ação penal, seja ela pública, com o oferecimento da denúncia pelo Ministério Público, ou privada, com a propositura da queixa-crime pelo ofendido. Daí a necessidade de no inquérito serem reunidos elementos que comprovem a materialidade do delito e que revelem indícios suficientes da autoria (art. $4^{\circ}$ do CPP).

Indiscutivelmente, os recursos tecnológicos aplicados no curso da investigação policial podem fornecer excelentes elementos, muitas vezes indispensáveis, à futura proposição da ação penal, agilizando os procedimentos investigatórios, tornando, assim, mais célere o exercício da persecutio criminis que, segundo Rogério Lauria Tucci ${ }^{21}$,

${ }^{20}$ FILHO, Juracy. Hackers invadem sites do Sistema de Segurança Pública do MA. Blog do Juracy Filho, 19/03/2018. Disponível em: <https://www.blogdojuracifilho.com.br/2018/03/19/hackers-invadem-sites-dosistema-de-seguranca-publica-do-ma/ $>$. Acesso em: 02 abr. 2018. Na mesma notícia, ainda consta que "Foi verificado o registro, durante a invasão que o fundo ficou preto, de um personagem de origem japonesa, o Naruto, fazendo o sinal de "OK" com o polegar. Ainda na postagem, houve ameaça, por parte do invasor, que prometeu também invadir o site da Polícia Militar do Maranhão, e avisou que só não o fez logo, porque estava offline (fora do ar). Mas também, o hacker invadiu os sites da Polícia Civil e Corpo de Bombeiros".

${ }^{21}$ TUCCI, Rogério Lauria. Direitos e garantias individuais no processo penal brasileiro. 4. ed. São Paulo: Revista dos Tribunais, 2011, p. 33. 
Consiste ele no poder-dever de promover a perseguição do indigitado autor da infração penal até o momento em que lhe seja imposta, definitivamente, com o trânsito em julgado da correspondente sentença condenatória, a sanção em lei estabelecida para a prática de fato por ela tida como penalmente relevante.

Cumpre consignar, entretanto, que nem sempre os instrumentos preliminares de investigação possuem a eficácia necessária para bem subsidiar a propositura da ação penal. A demora injustificada na conclusão do inquérito policial, por exemplo, pode ensejar o relaxamento da prisão por ofensa aos princípios da razoabilidade e da proporcionalidade. Nesse ponto, por exemplo, a legislação processual penal em vigor estabelece a necessidade de os laudos periciais serem concluídos no prazo de dez dias, sendo possível a prorrogação, mas somente em casos excepcionais, a teor do art. 160 do CPP. 22

No entanto, em virtude dos entraves hoje existentes, inclusive no que concerne à remessa de laudos periciais às delegacias, verifica-se considerável atraso no encaminhamento das perícias e, por conseguinte, na própria conclusão do inquérito policial, havendo notícias de que a elaboração e entrega de laudos periciais no Estado de São Paulo está demorando até um ano. Com efeito, verifica-se que

No Departamento de Homicídios e de Proteção à Pessoa (DHPP), apurou-se que mais de 700 laudos periciais ainda não foram entregues e, por esse motivo, estão travando a conclusão dos inquéritos. O Instituto de Criminalística (IC), por sua vez, possui mais de 300 laudos em atraso, enquanto o Instituto Médico-Legal (IML), mais de $400^{23}$.

Mas o problema não se resume às perícias. É possível considerar a existência de uma verdadeira crise sobre a sistemática dos instrumentos preliminares de investigação policial no Brasil, crise essa que assola os quadrantes da agilidade, celeridade e eficiência. Nesse tópico, Aury Lopes $\mathrm{Jr}^{24} \mathrm{faz}$ importante crítica às deficiências do sistema. Em suas palavras

\footnotetext{
${ }^{22}$ Art. 160. Os peritos elaborarão o laudo pericial, onde descreverão minuciosamente o que examinarem, e responderão aos quesitos formulados. Parágrafo único. O laudo pericial será elaborado no prazo máximo de 10 dias, podendo este prazo ser prorrogado, em casos excepcionais, a requerimento dos peritos.

${ }_{23}$ TOMAZ, Kleber; PIZA, Paulo Toledo. Laudos levam até 1 ano para serem concluídos e travam inquéritos em SP. Portal G1, 28/02/2013. Disponível em: < http://g1.globo.com/sao-paulo/noticia/2013/02/laudos-levam-ate1-ano-para-serem-concluidos-e-travam-inqueritos-em-sp.html> . Acesso em: 22 mar. 2018.

${ }^{24}$ LOPES JR., Aury. Direito processual penal. 10. ed., São Paulo: Saraiva, 2013, p. 254.
} 
[...] o inquérito policial está em crise. Os juízes apontam para a demora e a pouca confiabilidade do material produzido pela polícia, que não serve como elemento de prova na fase processual. Os promotores reclamam da falta de coordenação entre a investigação e as necessidades de quem, em juízo, vai acusar. $\mathrm{O}$ inquérito demora excessivamente e, nos casos mais complexos, é incompleto, necessitando de novas diligências, com evidente prejuízo à celeridade e à eficácia da persecução.

Prosseguindo, no ano de 2013, o Conselho Nacional do Ministério Público (CNMP), publicou um relatório referente a dados estatísticos de 2011, apontando que o Brasil tem mais de 3,8 milhões de inquéritos policiais ou notícias-crime sem a devida conclusão. Essa quantidade equivale a $72 \%$ do total de 5,3 milhões de inquéritos recebidos pelas Promotorias e Procuradorias estaduais e federais ${ }^{25}$.

Uma das razões pelas quais tais instrumentos preliminares de investigação não chegam a bom termo é o desvio de função a que são submetidos os policiais civis, notadamente no Estado de São Paulo. Verifica-se, na prática, que inúmeros agentes são direcionados a atividades eminentemente burocráticas, que pouco ou nada acrescem ao deslinde da investigação policial.

Nessa linha, por exemplo, há as constantes remessas de autos de prisão em flagrante, bem como de inquéritos já em andamento aos diversos Fóruns ${ }^{26}$ muitas vezes, apenas e tão somente para o magistrado deferir uma simples dilação prazo. ${ }^{27}$ Não se olvide, outrossim, o transtorno, burocracia e tempo perdido com a remessa e recebimento de laudos periciais de inúmeras espécies, que, obrigatoriamente, devem ser encartados nos autos do inquérito policial ou da ação penal.

Se já não fosse o bastante, agentes policiais ficam submetidos a inúmeras atribuições estranhas àquelas inerentes do cargo, tal como o transporte e a vigilância de presos em cadeias públicas, acarretando desvio de função, em franco prejuízo do

${ }^{25}$ BRASIL. Conselho Nacional do Ministério Público. Ministério público - um retrato. Disponível em: <http:// www.cnmp.gov.br/portal/images/stories/RetratoMP.pdf > . Acesso em: 15 mar. 2018.

${ }^{26} \mathrm{O}$ art. 306, $\S 1^{\mathrm{o}}$, do Código de Processo Penal, estabelece que, em até 24 (vinte e quatro) horas após a realização da prisão, será encaminhado ao juiz competente o auto de prisão em flagrante e, caso o autuado não informe o nome de seu advogado, cópia integral para a Defensoria Pública.

${ }^{27}$ Nos termos do art. $10, \S 3^{\circ}$, do Diploma Processual Penal, quando o fato for de difícil elucidação, e o indiciado estiver solto, a autoridade poderá requerer ao juiz a devolução dos autos, para ulteriores diligências, que serão realizadas no prazo marcado pelo juiz. 
escorreito deslinde das investigações ${ }^{28}$, o que inclusive pode gerar prejuízo ao erário público. Nesse contexto, é pacífica a orientação do Superior Tribunal de Justiça no sentido de que o servidor que desempenha função diversa daquela inerente ao cargo por ele formalmente ocupado tem direito a perceber as diferenças remuneratórias porventura existentes, sob pena de locupletamento indevido da administração, a teor da súmula 378.

Esse estado de coisas não é apenas prejudicial ao interesse público, dado o risco de diversos delitos não serem corretamente apurados, o que implicará numa provável absolvição por falta de provas, não sendo de se descartar também o perigo de vários crimes simplesmente prescreverem diante do lapso temporal transcorrido. Aliás, há notícia de que dois em cada três inquéritos policiais são arquivados por falta de provas ou prescrição ${ }^{29}$.

Existe igualmente prejuízo aos investigados, principalmente quando a demora não é proposital, ou seja, fruto de manobras engendradas pela própria defesa, por exemplo, com solicitações de diligências descabidas. Fora as hipóteses de torpeza, a demora na conclusão das investigações coloca o investigado numa situação de incômoda vulnerabilidade e incerteza quanto ao futuro, sendo certo que, não obstante o princípio da presunção de inocência possuir índole constitucional, é sabido que o fato de alguém estar sendo investigado no bojo de um inquérito policial significa uma pecha sobre a honradez e honestidade dessa pessoa.

Desse modo, é intuitivo perceber a necessidade de serem implantadas modificações na sistemática de processamento dos inquéritos policiais de maneira a resgatar a eficiência desse importante instrumento de investigação criminal. Em nosso entendimento, uma das ferramentas (não a única, obviamente) que poderia auxiliar nessa missão, é a virtualização do inquérito, com o abandono do papel, medida que inclusive se coaduna perfeitamente ao contexto informacional atualmente vivido pela humanidade. Aliás, as tecnologias necessárias para tanto já existem. No mínimo haveria ganho de tempo, pela desnecessidade do trâmite físico dos inquéritos entre a Polícia, o Judiciário e o Ministério Público. Igualmente, haveria economia de papel

\footnotetext{
${ }^{28}$ Com efeito, "É muito comum em delegacias por todo o Estado de São Paulo ocorrer desvio de função ou acumulo de função, como a de Agentes Policiais e Carcereiros fazendo a função de Investigadores ou de Escrivães de Polícia fazendo algumas funções de Delegados de Polícia, dentre outras" (Policial civil deve ser indenizado por desvio de função por acúmulo de titularidade. Sindicato dos Policiais Civis de Campinas e Região. Disponível em: < http://www.sinpolcampinas.org.br/exibe.php?id=38>. Acesso em: 22 mar. 2018).

${ }^{29}$ DOIS em cada três inquéritos policiais são arquivados por falta de provas ou prescrição. JOTA: Justiça, 18/08/2015. Disponível em: < https://www.jota.info/justica/policia-arquiva-23-dos-inqueritos-por-falta-de-provas-ou-prescricao-18082015 > . Acesso em: 22 mar. 2018.
} 
e de gastos com transporte e combustível, bem como a liberação de agentes para o trabalho investigativo propriamente dito.

\section{EXPERIÊNCIAS EM ANDAMENTO}

Atualmente existem alguns projetos de inquérito policial digital no país, ainda em fase de experimentação, mas sempre, contudo, visando à celeridade e modernização das diligências investigatórias. Tratando-se o inquérito policial de um procedimento preparatório da ação penal, embora dispensável, é bastante conveniente que ensaios sejam realizados para que se garanta a lisura e o normal desenvolvimento dos atos de Polícia Judiciária.

No Estado do Amazonas, em meados de 2013, a Primeira Delegacia Interativa ( $1^{\text {a }}$ DIP) e a Delegacia Especializada de Crimes Contra a Mulher enviaram para o Fórum de Manacapuru, por intermédio do sistema Projud (Processo Eletrônico do Judiciário), autos de prisão em flagrante, requerimentos de decretação de prisão preventiva, inquéritos policiais e termos circunstanciados, em importante iniciativa para superar as barreiras geográficas daquele Estado, o maior da Federação em extensão territorial e sabidamente pouco servido por estradas de rodagem. Além disso, no mesmo Estado, as cidades de Guajará e Presidente Figueiredo já possuem sistemas interligados entre os Fóruns e as respectivas Delegacias Policiais, dando, com isso, mais ligeireza aos procedimentos criminais. ${ }^{30}$

Já o Estado de Alagoas produziu o seu primeiro instrumento preliminar de investigação no formato digital, consistente em um inquérito policial instaurado para apurar uma tentativa de homicídio praticada em Maceió. O referido inquérito virtual foi assinado de maneira eletrônica com a utilização de certificação digital consoante padrão da Infraestrutura de Chaves Públicas Brasileira (ICP-Brasil). ${ }^{31}$

O procedimento adotado consistiu em fornecer certificados digitais para delegados e escrivães, capacitando-os para o sistema de peticionamento eletrônico

\footnotetext{
${ }^{30}$ BRASIL. Conselho Nacional de Justiça. Virtualização conecta Polícia Civil à Justiça em Manacapuru. Brasília, 21/08/2013. Disponível em < http://www.cnj.jus.br/noticias/judiciario/75824-virtualizacao-conecta-policia-civil -a-justica-em-manacapuru > . Acesso em: 24 mar. 2018.

${ }^{31}$ A Infraestrutura de Chaves Públicas Brasileira (ICP-Brasil) é uma cadeia hierárquica e de confiança que viabiliza a emissão de certificados digitais para identificação virtual do cidadão. Observa-se que o modelo adotado pelo Brasil foi o de certificação com raiz única, sendo que o ITI, além de desempenhar o papel de Autoridade Certificadora Raiz (AC-Raiz), também tem o papel de credenciar e descredenciar os demais participantes da cadeia, supervisionar e fazer auditoria dos processos (BRASIL. Instituto Nacional de Tecnologia da Informação. ICP-Brasil, 27/06/2017. Disponível em: < http://www.iti.gov.br/icp-brasil >. Acesso em: 02 abr. 2018.
} 
do Tribunal de Justiça de Alagoas, bem como no sistema de remessa de inquéritos policiais ao Ministério Público daquele Estado. Desse modo, o aludido inquérito policial foi remetido eletronicamente a uma das Varas Criminais do Poder Judiciário alagoano. ${ }^{32}$

Importante ressaltar outras iniciativas encetadas no Estado de São Paulo, em consonância com o Projeto 100\% Digital mencionado acima. A primeira delas, consistente em uma parceria estabelecida entre a Secretaria de Segurança Pública e o Tribunal de Justiça do Estado de São Paulo, que possibilitou o recebimento, na Vara de Violência Doméstica e Familiar contra a Mulher do Foro Regional do Butantã, do primeiro inquérito policial digital.

O resultado foi concretizado no final de 2015 , em razão de uma integração entre o Sistema de Automação da Justiça - SAJ, utilizado pelo Tribunal de Justiça do Estado de São Paulo, e aquele utilizado pela Polícia Civil paulista ${ }^{33}$.

Mais recentemente, a baixada santista foi a primeira Circunscrição Judiciária a atingir quase 4.000 inquéritos policiais no formato digital em trâmite, iniciativa do resultado entre a parceria da Secretaria de Segurança Pública do Estado e o Tribunal de Justiça que informa haver 36 Delegacias da Cidade de Santos totalmente integradas à solução de gestão dos processos judiciais.

Com apenas um comando no computador conectado à internet o inquérito policial digital é enviado do ambiente virtual policial ao seu destinatário, no caso, o juiz, para então ser despachado, tudo em questão de segundos. Em suma, como já dito acima, há economia de tempo e de recursos públicos. Nessa toada, segundo o delegado de polícia Joaquim Leitão Júnior ${ }^{34}$, do Estado do Mato Grosso,

As vantagens com a implantação do inquérito policial eletrônico são inegáveis como forma de celeridade na sua conclusão, a racionalização dos recursos humanos atualmente empregados no formato de papel com economia e utilização das demais ferramentas tecnológicas.

\footnotetext{
${ }^{32}$ AASP. Certificação digital viabiliza inquérito virtual. Disponível em: < http://processoeletronico.aasp.org.br/ certificacao-digital-viabiliza-inquerito-virtual/> . Acesso em: 18 mar. 2018.

33 SÃO PAULO (Estado). Tribunal de Justiça. SAJ Digital. Disponível em: < http://www.sajdigital.com.br/tribunalde-justica/inquerito-policial-digital/> . Acesso em: 22 mar. 2018.

${ }^{34}$ LEITÃO JR., Joaquim. O inquérito policial eletrônico e os desafios da polícia judiciária do futuro. GENJURÍDICO.COM.BR, 13/12/2017. Disponível em: < http://genjuridico.com.br/2017/12/13/inquerito-policial-eletronico-policia-judiciaria-do-futuro/> . Acesso em: 04 abr. 2018. Ainda segundo o autor: "Outra vantagem também dessa informatização, é de que o laudo pericial já seria inserido diretamente no sistema informatizado pela Perícia, integrando o inquérito policial digital, sem contar na modernização que acarreta à Polícia Judiciária do futuro".
} 
Joaquim Leitão Júnior dá notícia, ainda, que no âmbito do Estado do Mato Grosso, "a implantação do Inquérito Policial Eletrônico, está em andamento para sua formatação e a previsão é de que em breve a Polícia Judiciária [...] possa contar com este importante instrumento no combate e repressão à criminalidade". Portanto, ao que tudo indica, a adoção da forma eletrônica para o inquérito policial parece ser uma tendência que aos poucos vai se espalhando pelo país.

\section{CONCLUSÕES}

O inquérito policial e o termo circunstanciado são procedimentos de natureza inquisitiva que objetivam a colheita de provas quando da ocorrência de um delito e o esclarecimento de sua autoria. Devido a sua natureza inquisitiva, dado não observar o princípio do contraditório, não obstante os advogados das pessoas investigadas poderem acompanhar o desenrolar das investigações, é considerado como mero ato preparatório da ação penal.

Ainda que o Código de Processo Penal faça alusão à necessidade de as peças do inquérito ser reduzidas a escrito ou datilografadas, considerando a evolução tecnológica trazida pela sociedade da informação, não se pode olvidar que tal conteúdo, ainda que vigente, resta ultrapassado, nada impedindo que meios eletrônicos sejam utilizados como suporte à investigação criminal.

Todavia, seja o inquérito materializado em papel ou em meio eletrônico, deve sempre ser processado sob sigilo, de maneira a não prejudicar o bom desenlace do trabalho investigativo policial (o que atende ao interesse público), bem como para preservar a intimidade e a honra dos investigados e das vítimas.

Observa-se que a atual sistemática do inquérito policial se encontra em crise, com destaque para a elevada demora na finalização dos trabalhos e o excesso de investigações abertas sem conclusão, com graves prejuízos à eficiência da persecução penal. Nesse ponto, o Conselho Nacional do Ministério Público (CNMP) apontou que, em 2011, no Brasil, havia mais de 3,8 milhões de inquéritos policiais ou notícias-crime sem a devida conclusão, quantidade equivalente a $72 \%$ do total de 5,3 milhões de inquéritos recebidos pelas Promotorias e Procuradorias estaduais e federais.

Nesse contexto, a adoção da forma eletrônica pode conferir maior celeridade aos inquéritos, uma vez que elimina a necessidade de deslocamento físico 
dos procedimentos entre a Polícia, o Ministério Público e o Judiciário, o que sempre envolve atos burocráticos como registros em livros de saída e entrada etc. Outra vantagem é a economia de papel e de gastos com o transporte. Adicionalmente, os agentes deslocados para a realização dessas tarefas podem ser deslocados para atividades ligadas diretamente às investigações em curso. Além disso, advogados e peritos não necessitam deslocar-se às delegacias de polícia, na medida em que a consulta aos autos e a remessa de laudos podem ser ultimadas por meio das redes eletrônicas.

Nota-se que o Brasil já conta com algumas experiências de virtualização do inquérito policial, destacando-se os Estados do Amazonas, Alagoas e São Paulo, sendo que a baixada santista foi a primeira Circunscrição Judiciária a atingir quase 4.000 inquéritos policiais no formato digital em trâmite.

No entanto, levando em conta que o meio virtual não é imune a ataques, inclusive havendo notícias de invasão de sites e sistemas informáticos de órgão públicos, tribunais e da própria polícia, a questão da segurança dos dados, tanto os armazenados quanto aqueles em trânsito, deve ser sempre priorizada, de modo a evitar vazamentos ilícitos que podem prejudicar gravemente a respeitabilidade social de investigados e vítimas, o que pode se tornar irreversível se houver propagação de elementos sensíveis do inquérito (conteúdo de depoimentos, fotografias, laudos etc.) por meio de redes computacionais eletrônicas.

\section{REFERÊNCIAS}

AASP. Certificação digital viabiliza inquérito virtual. Disponível em: $<$ http://processo eletronico.aasp.org.br/certificacao-digital-viabiliza-inquerito-virtual/ $>$. Acesso em: 18 mar. 2018.

BARRETO JR., Irineu Francisco. Atualidade do conceito de sociedade da informação para a pesquisa jurídica. In: PAESANI, Liliana Minardi (Coord.). 0 direito na sociedade da informação. São Paulo: Atlas, 2007, p. 61-77.

BRASIL. Casa Civil da Presidência da República. Instituto Nacional de Tecnologia da Informação. ICP-Brasil. Disponível em: < http://www.iti.gov.br/icp-brasil> . Acesso em: 21 abr. 2017. 
BRASIL. Código de Processo Penal. Decreto-Lei no 3.689, de 03 de outubro de 1941. Presidência da República, 1941. Disponível em: < http://www.planalto.gov.br/ ccivil_03/decr eto-lei/Del3689Compilado.htm>. Acesso em: 9 set. 2017.

BRASIL. Conselho Nacional de Justiça. Virtualização conecta Polícia Civil à Justiça em Manacapuru. Brasília, 21/08/2013. Disponível em: < http://www.cnj.jus.br/ noticias/judiciario /75824-virtualizacao-conecta-policia-civil-a-justica-em-manacapuru>. Acesso em: 24 mar. 2018.

BRASIL. Conselho Nacional do Ministério Público. Ministério público: um retrato. Brasília, 2012. Disponível em: < http://www.cnmp.gov.br/portal/images/stories/RetratoMP.pdf $>$. Acesso em: 15 mar. 2018.

BRASIL. Constituição da República Federativa do Brasil. Brasília, DF: Senado, 1988. Disponível em: < http://www.planalto.gov.br/ccivil_03/constituicao/constituicaocompilado. htm $>$. Acesso em: 9 set. 2017.

BRASIL. Estratégia Nacional de Justiça e Segurança Pública. Meta 2: a impunidade como alvo - diagnóstico da investigação de homicídios no Brasil. Brasília, 2012. Disponível em: < http://www.cnmp.mp.br /portal/images/stories/Enasp/relatorio_ enasp_FINAL.pdf>. Acesso em: 03 abr. 2018.

BRASIL. Instituto Nacional de Tecnologia da Informação. ICP-Brasil, 27/06/2017. Disponível em: < http://www.iti.gov.br/icp-brasil> Acesso em: 02 abr. 2018.

BRASIL. Lei $\mathrm{n}^{\mathbf{0}} \mathbf{8 . 9 0 6}$, de 04 de julho de 1994. Dispõe sobre o Estatuto da Advocacia e a Ordem dos Advogados do Brasil (OAB). Disponível em: < http://www. planalto.gov. br/ccivil_03/LEIS/L8906.htm > . Acesso em: 11 mar. 2018.

BRASIL. Lei $\mathrm{n}^{\mathrm{0}} \mathbf{9 . 2 9 6}$, de 24 de julho de 1996. Regulamenta o inciso XII, parte final, do art. $5^{\circ}$ da Constituição Federal. Disponível em: < http://www.planalto.gov. br/ccivil_03/leis/L9296. htm>. Acesso em: 11 mar. 2018.

BRASIL. Lei $\mathrm{n}^{\circ}$ 9.099, de 26 de setembro de 1995. Dispõe sobre os Juizados Especiais Cíveis e Criminais e dá outras providências. Disponível em: < http://www. planalto.gov.br/ccivil_03/leis/L9099.htm > . Acesso em: 11 mar. 2018. 
BRASIL. Lei $\mathrm{n}^{\mathrm{o}}$ 11.419, de 19 de dezembro de 2016. Dispõe sobre a informatização do processo judicial; altera a Lei ํㅜㄴ 5.869, de 11 de janeiro de 1973 - Código de Processo Civil; e dá outras providências. Disponível em: < http://www.planalto.gov. br/ccivil_03/_ato2004-2006/2006/lei/111419.htm >. Acesso em: 22 mar. 2018.

BRASIL. Lei $\mathrm{n}^{\mathbf{0}} \mathbf{1 1 . 9 0 0}$, de 08 de janeiro de 2009. Altera dispositivos do Decreto -Lei n⿳⺈ 3.689, de 03 de outubro de 1941 - Código de Processo Penal, para prever a possibilidade de realização de interrogatório e outros atos processuais por sistema de videoconferência, e dá outras providências. Disponível em: < http://www.planalto.gov.br/ccivil_03/_ato2007-2010/2009/lei/111900.htm >. Acesso em: 22 mar. 2018.

BRASIL. Lei $n^{0} \mathbf{1 2 . 8 5 0}$, de 02 de agosto de 2013. Define organização criminosa e dispõe sobre a investigação criminal, os meios de obtenção da prova, infrações penais correlatas e o procedimento criminal. Disponível em: <http://www.planalto. gov.br/ccivil_03/_ato2011-2014/2013/lei/112850.htm > . Acesso em: 22 mar. 2018.

BRASIL. Superior Tribunal de Justiça. Súmula no 378. Disponível em: <http:// www. stj.jus.br/SCON/sumulas/doc.jsp?livre= $@$ num $=\% 27378 \% 27>$. Acesso em: 25 mar. 2018.

BRASIL. Supremo Tribunal Federal. Súmula vinculante $\mathbf{n}^{\mathbf{0}}$ 14. Disponível em: $<$ http://portal. stf.jus.br/textos/verTexto.asp?servico=jurisprudenciaSumulaVinculante $>$. Acesso em: 22 mar. 2017.

DOIS em cada três inquéritos policiais são arquivados por falta de provas ou prescrição. JOTA: Justiça, 18/08/2015. Disponível em: < https://www.jota.info/justica/policia-arquiva-23-dos-inqueritos-por-falta-de-provas-ou-prescricao-18082015> . Acesso em: 22 mar. 2018.

FILHO, Juracy. Hackers invadem sites do Sistema de Segurança Pública do MA. Blog do Juracy Filho, 19/03/2018. Disponível em: < https://www.blogdojuracifilho.com. br/2018 /03/19/hackers-invadem-sites-do-sistema-de-seguranca-publica-do-ma/>. Acesso em: 02 abr. 2018.

HERSCOVICI, Alain. A sociedade em rede e a universalização do mercado: elementos de análise. Revista Electrónica Internacional de Economía de las Tecnologías 
de la Información y de la Comunicación, n. 2, jul./ago. 2000. p. 23-40. Disponível em: < https://seer.ufs.br/index.php/eptic/article/ view/320/295> . Acesso em: $23 \mathrm{fev}$. 2018.

JUNQUEIRA, Gustavo Octaviano Diniz; FULLER, Paulo Henrique Aranda. Legislação penal especial. 6. ed. São Paulo: Saraiva, 2010. vol. 1.

LEITÃO JR., Joaquim. O inquérito policial eletrônico e os desafios da polícia judiciária do futuro. GENJURIDICO.COM.BR, 13/12/2017. Disponível em: < http:// genjuridico.com.br/ 2017/12/13/inquerito-policial-eletronico-policia-judiciaria-dofuturo/> . Acesso em: 04 abr. 2018.

LÉVY, Pierre. Cibercultura. 2. ed. São Paulo: Editora 34, 2007.

LOPES JR., Aury. Direito processual penal. 10. ed., São Paulo: Saraiva, 2013.

MATTELART, Armand. The information society. Tradução de Susan G. Taponier e James A. Cohen. London: SAGE Publications, 2003.

PAIERO, Denise. Escola base: um caso que não pode ser esquecido. Portal Mackenzie, 13/04/2017. Disponível em: < http://portal.mackenzie.br/fakenews/noticias/ arquivo/artigo/ escola-base-um-caso-que-nao-pode-ser-esquecido/ $>$. Acesso em: 02 abr. 2018.

POLICIAL civil deve ser indenizado por desvio de função por acúmulo de titularidade. Sindicato dos Policiais Civis de Campinas e Região. Disponível em: < http:// www.sinpol campinas.org.br/exibe.php?id=38>. Acesso em: 22 mar. 2018

ROSSINI, Augusto Eduardo de Souza. Breve ensaio sobre a tutela punitiva na sociedade da informação, suas esferas de proteção e recentes conquistas. In: PAESANI, Liliana Minardi (Coord.). O Direito na sociedade da informação II. São Paulo: Atlas, 2008.

SÃO PAULO (Estado). Secretaria de Segurança Pública. Dados estatísticos do Estado de São Paulo. Disponível em: < http://www.ssp.sp.gov.br/Estatistica/Pesquisa. aspx> . Acesso em: 25 mar. 2018. 
SÃO PAULO (Estado). Tribunal de Justiça. 100\% digital. Disponível em: < http:// www.tjsp. jus.br/CemPorCentoDigital> . Acesso em: 22 mar. 2018.

SÃO PAULO (Estado). Tribunal de Justiça. SAJ Digital. Disponível em: < http://www. sajdigital.com.br/tribunal-de-justica/inquerito-policial-digital/> . Acesso em: $22 \mathrm{mar}$. 2018.

SIQUEIRA JÚNIOR, Paulo Hamilton. Habeas data: remédio jurídico da sociedade da informação. In: PAESANI, Liliana Minardi (Coord.). 0 direito na sociedade da informação. São Paulo: Atlas, 2007. p. 251-274.

TOMAZ, Kleber; PIZA, Paulo Toledo. Laudos levam até 1 ano para serem concluídos e travam inquéritos em SP. Portal G1, São Paulo. Disponível em: < http://g1.globo. com/sao-paulo/noticia/2013/02/laudos-levam-ate-1-ano-para-serem-concluidos-e-travam-inqueritos-em-sp.html>. Acesso em: 22 mar. 2018.

TUCCI, Rogério Lauria. Direitos e garantias individuais no processo penal brasileiro. 4. ed., São Paulo: Revista dos Tribunais, 2011.

Recebido em: 10 de abril de 2018 Aceito em: 27 de julbo de 2018 